\title{
Management of advanced adult congenital heart disease
}

\section{Sarah E. Bowater}

SpR Cardiology, Queen Elizabeth Hospital, Birmingham, United Kingdom

Address for correspondence:

Dr Sarah Bowater

University Hospital Birmingham

NHS Foundation Trust

Queen Elizabeth Hospital

Edgbaston

Birmingham

United Kingdom

\section{Email:sarah.bowater@uhb.nhs.uk}

\section{INTRODUCTION}

Due to advances in cardiac surgery and paediatric cardiology, increasing numbers of children born with congenital heart disease (CHD) are surviving into adulthood. ${ }^{(1-3)}$ As a result there are now more adults than children living with $\mathrm{CHD} .(2,45)$, Furthermore, an increasing number of adults are surviving with the more severe forms of CHD with Marelli, et al. reporting the prevalence of severe CHD in adults increasing by $85 \%$ between 1985-2000 compared to just $22 \%$ in the paediatric population. ${ }^{(4)} \mathrm{A}$ recent report by Tutarel, et al. from the UK also recently reported an increase of 6-7 fold in patients with moderate to severe defects since $2000 .^{(6)}$

Only the very simple lesions are truly "cured" by surgical or interventional procedures with the majority of patients remaining at long term risk of complications including arrhythmias, ventricular failure and premature death.(5) Despite this, mortality has shifted away from infancy to adulthood with an increasing age of death reported. ${ }^{(7)}$ Whilst the age of death is increasing, this population still has an excess mortality compared to their healthy counterparts. ${ }^{(3,8)}$ The commonest cause of death in adults with CHD is heart failure, accounting for up to $40 \%$ of all deaths with sudden cardiac death also being a major cause. ${ }^{(3,8-10)}$ Although the majority of deaths are cardiac, related to the underlying CHD, non-cardiac mortality was also two fold that expected.(3) Furthermore, as this population continues to age, they will also be at risk of significant medical comorbidities. ${ }^{(6,1)}$

\section{ABSTRACT}

There are increasing numbers of adults with congenital heart disease. These patients remain at lifelong risk of complications including heart failure, arrhythmias and premature death. This review examines the management of those patients with advanced disease, with particular reference to patients with either a systemic right ventricle or a univentricular circulation. Drugs used to treat left ventricular dysfunction in acquired heart disease have been shown to have little benefit in this setting. There are, however, promising results from small trials looking at selective pulmonary vasodilators in patients with a previous Fontan operation. Whilst there is evidence of a benefit with implantable cardiac defibrillators and cardiac resynchronisation, there remains a lack of clear guidelines as to which patients will benefit from these invasive therapies. Cardiac transplantation in these patients is associated with an increased early mortality but the long term outcome is similar to those with acquired heart failure. Transplantation however, is limited by both the patient's suitability and the availability of a matched organ. End of life care should be discussed with all patients with advanced disease and ideally this should be done early on and in parallel to other therapies. SAHeart 20। 3; 1 0:626-634

As surgical techniques continue to develop, for example as seen with the Norwood procedure for hypoplastic left heart syndrome, the number of patients with the most complex forms of CHD will continue to increase along with their associated long term complications. Our ability to manage these patients appropriately, therefore, must also develop alongside. The purpose of this review is to examine the management of these patients once they have developed advanced disease, including drug therapy, devices, transplant and end of life care. In particular, the unique problems posed by patients with a systemic right ventricle (RV) and univentricular circulations are discussed.

\section{DRUG THERAPY IN HEART FAILURE}

In patients with complex congenital heart disease, either palliated or unoperated, the development of ventricular dysfunction and clinical heart failure are common and as discussed above, is a common cause of morbidity and mortality in this population.(7) Causes of ventricular dysfunction include longstanding volume or pressure overload, cyanosis or surgical insult. It is usually a chronic 
process with the development of clinical features of heart failure often occurring after a period of asymptomatic ventricular failure. Drug therapy is often first line in the management of these patients, with experience gained from acquired heart failure often being applied. However, patients with congenital heart disease were excluded from all the major chronic heart failure studies and, due to their unique anatomical and physiological abnormalities, should be considered a very different population. To date, though, most trials in this population involve small patient numbers and frequently use surrogate end points. ${ }^{(12)}$ Two groups of patients who pose specific problems in the management of ventricular failure are those with a systemic right ventricle (RV) and a univentricular circulation.

The RV does not behave like a normal left ventricle (LV) when in the subaortic position, either in congenitally corrected transposition of the great arteries (CTGA) or transposition of the great arteries (TGA) with a previous atrial switch. As a result systemic RV dysfunction is common in these adult patients with the prevalence increasing with age. ${ }^{(13-16)}$ Whilst the number of patients with a previous atrial switch is decreasing due to the introduction of the arterial switch operation in the $1980 \mathrm{~s},{ }^{(12)}$ the current population is ageing and will therefore be at a higher risk of developing long term sequelae of their condition, including ventricular dysfunction, atrial arrhythmias and death.

The systemic RV is known to have extensive myocardial fibrosis and hypertrophy and these correlate well with the degree of ventricular dysfunction. (17-19) Angiotensin converting enzyme inhibitors (ACEIs) and angiotensin receptor blockers (ARBs) have previously been shown to decrease myocardial fibrosis and attenuate ventricular remodelling with a resultant increase in myocardial function and decrease in mortality in patients with both asymptomatic and symptomatic left ventricular dysfunction. (20-23) There have been several small trials using ACEls and ARBs in patients with a systemic $\mathrm{RV}$ but results have been disappointing. ${ }^{(17,24,25)}$ A recent placebo-controlled study from the Netherlands studied the effect of the ARB valsartan on patients with either a previous atrial repair for TGA or CTGA.(26) Eighty eight patients were enrolled, 44 receiving valsartan and 44 placebo with a follow up of three years. The authors found no difference in MRI-derived RVEF, quality of life or exercise capacity between the valsartan and placebo group.

Similarly, beta blockers are known to improve LV function, reverse remodelling and reduce morbidity and mortality in patients with chronic LV dysfunction. ${ }^{(27,28)}$ Josephson, et al. studied the effect of beta blockers in patients with a previous Mustard repair of TGA and found a trend towards improved functional status and reduction in tricuspid regurgitation. ${ }^{(29)}$ Giardini, et al. also reported a trend towards a reduction in $\mathrm{RV}$ volumes and increase in ejection fraction in patients with a systemic RV receiving carvedilol. ${ }^{(30)}$ However, both of these studies were small single centre trials involving very small patient numbers. A larger study by Doughan, et al. retrospectively examined all patients in their centre with a systemic RV receiving carvedilol or metoprolol. ${ }^{(3)}$ They included 31 patients but were unable to demonstrate an effect on either RV ejection fraction or RV volumes, although they do report an improvement in functional class. Thus, at present evidence remains lacking for the use of beta blockers in systemic RV dysfunction from the current data available. They are however commonly used for the treatment or prevention of atrial arrhythmias in this patient group. A recent preliminary study looked at the effect of eplerenone, a selective aldosterone antagonist, on patients with a systemic RV. ${ }^{(32)}$ They showed that whilst it was associated with reduced levels of collagen turnover biomarkers, suggesting a reduction in myocardial fibrosis, there were no changes in MRI derived parameters of ventricular function.

Clinical heart failure in patients with a previous Fontan operation is increasingly common with age occurring in up to $40 \%$ of patients 16 years after repair. ${ }^{(14)}$ It is characterised by increasing central venous pressures and decreasing cardiac output. ${ }^{(33)}$ Again, progressive myocardial fibrosis has been identified and is associated with ventricular dysfunction ${ }^{(34)}$ and thus neurohormonal modulation, such as with beta blockers, has been suggested as a logical approach. ${ }^{(33)}$ Ishibashi, et al. retrospectively evaluated 5 I paediatric and young adult patients with evidence of heart failure and ventricular dysfunction. ${ }^{(35)}$ All patients received carvedilol and were followed up for a mean of I I months. They demonstrated a reduction in cardiothoracic ratio and an increase in ejection fraction following carvedilol therapy, along with a reduction in required diuretic dose and an increase in functional class in the $>15$ year old group. Two studies have examined the use of ACEls in a univentricular circulation. Hsu, et al. gave infants in the first year of life enalapril to improve haemodynamic status and ventricular function but showed no benefit. ${ }^{(36)}$ Koulati, et al. similarly found no benefit on ventricular function or exercise capacity after giving ${ }^{(37)}$ children and young adults with a Fontan circulation enalapril for 10 weeks. ${ }^{(38)}$

Elevated pulmonary vascular resistance (PVR) is also associated with failure of the Fontan circulation ${ }^{(37)}$ with possible causes including lack of pulsatile flow in the pulmonary vasculature, microemboli and chronic overexpression of vasoconstrictors such as endothelin-I. ${ }^{(39)}$ A reduction in PVR would increase pulmonary 
blood flow and cardiac filling and thus stroke volume in the presence of normal contractility. ${ }^{(40)}$ There is therefore interest in the role of selective pulmonary vasodilators in patients with a failing Fontan circulation. Ovraet, et al. found no change in exercise capacity after three months of bosentan, an endothelin receptor antagonist, in children and young adults. ${ }^{(41)}$ However, our group demonstrated that bosentan produced a small increase in longitudinal ventricular function and an improvement in NYHA functional class after six months of therapy. ${ }^{(42)}$ However, numbers were small in both of these studies highlighting the need for larger randomised controlled trials to study the effect on this population. Trials with the phoshpodiesterase-5 inhibitor, sildenafil, have so far been more promising. Goldberg, et al. looked at the effect on exercise performance of six weeks of sildenafil on 28 children and young adults with a Fontan circulation. ${ }^{(40)}$ Whilst they failed to show an increase in peak oxygen consumption, they did find a significant improvement in ventilator efficiency during peak and submaximal exercise. A further study gave sildenafil to a similar population and after just one week demonstrated and increase in ventricular systolic elastance and improved ventriculo-arterial coupling. ${ }^{\left({ }^{(3)}\right.}$

\section{IMPLANTABLE CARDIAC DEFIBRILLATORS (ICDs)}

Arrhythmias are common in adult congenital heart disease (ACHD) patients and are an important determinant in the morbidity and mortality of this population ${ }^{(3,8-10,44)}$ with the risk of late sudden cardiac death (SCD) being 25-100 times greater than that of an aged matched control population, ${ }^{(45)}$ the risk increasing after the second decade following surgery. Arrhythmias may be intrinsic to the underlying abnormality, such as an accessory pathway in Ebstein's anomaly, or due to long term sequelae from its palliation, such as extensive suture lines, chronic haemodynamic disturbances or long term cyanosis. ${ }^{(46,47)}$ The risk of arrhythmias and SCD appears to be highest in those with surgically repaired Tetralogy of Fallots (TOF), ${ }^{(48)}$ and TGA with an atrial switch. ${ }^{(45,49,50)}$

Czosek, et al. studied 589 Holter monitors in 189 patients with CHD. ${ }^{(51)}$ They found that non-sustained ventricular tachycardia (NSVT) was associated with SCD in patients with TOF but not in those with previous atrial switches or Fontan operation. They concluded that Holter monitors overall have a low positive predictive value for clinically significant arrhythmias but a high negative predictive value. Other high risk features of SCD identified in patients with TOF include a QRS duration $>180 \mathrm{~ms}$ on a resting ECG, ${ }^{(52)}$ a lengthening QRS late after surgery ${ }^{(53)}$ and inducible sustained ventricular tachycardia (VT) during programmed ventricular stimulation. ${ }^{(54)}$

Kammeraad, et al. also found that the presence of NSVT on Holter ECG monitoring was not predictive of SCD in patients with TGA / atrial switch. ${ }^{(49)}$ They did however demonstrate an increase risk in the presence of symptoms and a previously documented atrial arrhythmia. Scwerzman, et al. comment that sustained VT and SCD is more common in those patients with a previous Mustard operation than previously described and is associated with increasing age, severe systemic ventricular dysfunction and a QRS duration $>140 \mathrm{~ms}$. $^{(50)}$

Whilst clear guidelines and indications exist for patients with ischaemic or dilated cardiomyopathy, there is a lack of universal criteria regarding risk stratification and indications for implantation of ICDs in ACHD patients. Even patients with repaired TOF have an incidence of SCD of only $2 \%$ per decade ${ }^{(46)}$ thus large randomised, prospective studies looking at outcomes of ICDs on mortality are difficult.

Even in the presence of high risk features, concern remains regarding the implantation of ICDs in these patients with several studies reporting high rates of complications, including inappropriate shocks in $21-47 \%$ of patients, mostly due to atrial tachyarrhythmias, T-wave over sensing or lead failure. ${ }^{(55-59)}$

Khanna, et al. reviewed all transvenous ICD implantations performed in ACHD patients at the Mayo clinic, United States, between 1991 and 2008. ${ }^{(60)}$ They report 85 devices in 73 patients with the commonest underlying diagnosis being TOF in 44\% cases. They report a low rate of implant related and long term complications with appropriate shocks occurring in 19\% of all patients. Appropriate shocks were associated with elevated pressures in the subpulmonic ventricle. They also found that inappropriate shocks occurred in only 15\% of patients which is lower than that reported in previous studies. A multi-centre European study by Koyak, et al. looked at 136 patients with ACHD who received an ICD. ${ }^{(61)}$ Again, the commonest diagnosis was TOF. They, however, found a much higher rate of implantation related complications as well as inappropriate shocks occurring in 30\% patients. Higher appropriate shock rates were also described with $29 \%$ of patients overall receiving at least one appropriate shock. Thus, despite a high reported complication rate, they conclude that ICDs are useful in the prevention of SCD in this population. 
Specific problems can arise in pacing patients with ACHD including no venous access to the heart, altered haemodynamics from long standing valvular disease making lead placement difficult, extensive scar tissue from previous surgery and small vessel size. ${ }^{(59)}$ Furthermore, residual intra-cardiac shunts lead to a risk of thrombus and subsequent systemic embolisation. Thus, in some patients, epicardial pacing may need to be considered. More recently the development of a subcutaneous ICD has added a further option for these patients. ${ }^{(62,63)}$ They consist of a pulse generator and subcutaneous electrode and negates the need for transvenous access. However, they have no integrated pacing function thus are not suitable if there is a risk of bradyarrhythmia. They may also increase the number of appropriate shocks delivered due to the absence of anti-tachycardia pacing.

Finally, these patients are often young and active. The psychological burden of ICD implantation may be greater than in older patients with acquired disease, with increased levels of depression and anxiety. ${ }^{(59,64,65)}$ These may be further increased in the occurrence of inappropriate shocks. Furthermore, they are committed to numerous generator changes and possible lead replacements throughout their life. It is thus vital that they receive appropriate counselling prior to implantation

\section{CARDIAC RESYNCHRONISATION THERAPY (CRT)}

The use of cardiac resynchronisation therapy in heart failure secondary to ischaemic and dilated cardiomyopathies is now well established with clear indications and guidelines. ${ }^{(66,67)}$ Its role in congenital heart disease, however, is less well defined and it may not be appropriate to extrapolate the findings of the large trials performed in acquired heart failure to this population. ${ }^{(68,69)}$ ACHD patients are a heterogeneous population and frequently have different forms of dyssynchrony, including a predominance of RBBB. ${ }^{(47)}$ They are also more likely to have subpulmonic ventricular dysfunction or have a systemic right ventricle or even a univentricular circulation. Further complicating factors include patient selection, transvenous lead access and access to the chamber or coronary sinus. ${ }^{(47,69)}$ As a result the evidence is limited to small studies or case studies.

Janousek, et al. in 2009 reported on 109 paediatric or young patients with CHD, median age 16.9 years, in a multicentre European study. ${ }^{(70)}$ This cohort included 36 patients with a systemic RV and four with a single ventricular circulation. The majority of patients had interventricular dyssynchrony secondary to single site pacing and only $41 \%$ had a transvenous approach. Their results show a decrease in systemic ventricular dimensions, an increase in systemic ventricular ejection fraction and an improvement in INYHA score. They found that the strongest predictor of an improvement in ventricular function is the presence of a systemic left ventricle. They further hypothesise that systemic RVs show less improvement due to the higher associated degree of systemic AV valve regurgitation seen. Similar results were shown by Dubin, et al. who demonstrated a benefit in patients with both systemic left and right ventricles. ${ }^{(71)}$ In their study, however, no benefit was demonstrated in univentricular circulations. They comment though that only $54 \%$ of their patients met the ejection fraction and QRS criteria used in adult acquired disease studies, thus concluding that the indications in the ACHD population differ from those in ischaemic and dilated cardiomyopathy and remain unclear.

The indication for CRT in failing systemic RVs remains uncertain and is also associated with specific difficulties regarding transvenous access and lead placement. Systemic ventricular dysfunction is increasingly common over time in patients with a previous Mustard or Senning repair.(14,15) Similarly, most patients with congenitally corrected TGA will develop some degree of RV dysfunction, usually occurring by the third decade of life. ${ }^{(16)}$ Janaousek, et al. in 2004 studied 8 patients with a systemic RV who underwent CRT therapy. ${ }^{(72)}$ They demonstrated a decrease in QRS duration and interventricular delay and increased RV filling time and ejection fraction. However, as in the other studies discussed above, the majority of patients had single site pacing induced ventricular dyssynchrony as the indication for CRT, making the interpretation of the results for unpaced patients unclear. Similar to their later paper, discussed above, Janousek, et al. noted no change in the severity of right $A V$ valve regurgitation with CRT therapy. Thus, for systemic right ventricles, it may be that CRT implantation should be considered as an adjunct to right $A V$ valve intervention. ${ }^{(69,70)}$

\section{CARDIAC TRANSPLANTATION IN ACHD}

As increasing numbers of patients born with complex congenital heart disease reach adulthood, there will be an inevitable rise in the number of patients who develop advanced disease in whom conventional medical and surgical therapy has failed, with an estimated $10-20 \%$ of all patients with complex ACHD eventually demonstrating the need for a transplant. ${ }^{(73)}$ In many of these 
patients, heart or heart and lung transplantation is the only definitive treatment to improve survival and quality of life. ${ }^{(74)}$ Transplantation in patients with $A C H D$, however, has previously been perceived to be associated with poor outcome, when compared to other indications ${ }^{(75.76)}$ with Taylor, et al. stating "the diagnosis of $A C H D$ is a powerful risk factor for death at one year after transplant". (77) Problems specific to this population include complex anatomy often with multiple previous operations ${ }^{(74,76,78)}$ and an elevated pulmonary vascular resistance (PVR), a known risk factor for early donor organ failure. ${ }^{(79)}$ Further to these, HLA sensitisation is common, especially in those patients who have undergone previous surgery with a homograft. ${ }^{(80)} \mathrm{HLA}$ sensitisation, as indicated by elevated panel reactive antibodies (PRA), is associated with a worse outcome following transplant, especially for those with a PRA $>25 \%$, as well as decreased chances of getting a successful organ match. ${ }^{(81)}$

Despite these problems, the numbers of patients with $\mathrm{CHD}$ being referred for transplantation has increased over the past I 5 years. ${ }^{(74,78)}$ However, the overall proportion of transplants for underlying $\mathrm{CHD}$ remains small and account for just $2 \%$ of all transplants performed. ${ }^{(82)}$ Thus, many studies are small, single centre studies.

Irving, et al. looked at all adults with CHD who underwent transplantation in a single UK centre. ${ }^{(76)}$ They report on 37 patients, $41 \%$ of whom had a univentricular circulation and $22 \%$ had TGA with a previous Mustard or Senning repair. They found a 30 day survival of $70.3 \%$ which was higher than patients with other indications; however their long term survival was comparable. Two larger studies from the US examined all transplants recorded in a nationwide registry and database. ${ }^{(74,78)}$ However, unlike Irving, et al., the type of CHD was not recorded. Davies, et al. identified I 035 adult patients with $\mathrm{CHD}$ who were listed for primary cardiac transplantation (2.5\% of the total number). ${ }^{(78)}$ They found that patients with $\mathrm{CHD}$ were on the waiting list for a longer time and, again demonstrated a higher early mortality in those with $\mathrm{CHD}$ (18.9\% vs 9.6\%) but an equivalent 10 year mortality (52.8\% vs 53.6\%). Similar results were also found by Patel, et al. who further reported that patients with $\mathrm{CHD}$ who underwent transplantation had significantly longer intraoperative ischaemic times. ${ }^{(74)}$ Furthermore they noted that the underlying causes for the excess early mortality included complex anatomy, right ventricular failure due to elevated PVR and a more debilitated condition prior to surgery.

Patients with a univentricular circulation account for the greatest number of $\mathrm{CHD}$ referrals for cardiac transplantation from the age of six months to adulthood. ${ }^{\left({ }^{83}\right)}$ However, patients with two ventricle hearts have been shown to have better outcome than those with single ventricle hearts. ${ }^{(84)}$ Furthermore, Griffiths, et al. demonstrated a worse outcome in patients with a Fontan circulation who underwent cardiac transplantation for failed Fontan physiology rather than primary ventricular dysfunction $(96.1 \%$ vs $89 \%$ one year survival). ${ }^{(85)}$ They go on to suggest that these patients should be considered for transplantation at an earlier stage of their disease or considered for alternative medical or surgical interventions.

It is clear that patients with CHD are a heterogeneous population and it is difficult to apply results from studies of patients undergoing transplantation for acquired cardiac disease. The criteria for referring these patients may not yet be properly defined resulting in some patients being listed too late. ${ }^{(78)}$ Furthermore, due to the complex issues associated with these patients and the relatively small numbers involved, these patients should be managed in large centres with the necessary experience and expertise to optimise their outcome. ${ }^{(76)}$

\section{VENTRICULARASSIST DEVICES}

The use of ventricular assist devices (VADs) is becoming increasingly widespread in patients with acquired heart failure ${ }^{(86)}$ as either a bridge to transplant or recovery. ${ }^{(79,87-89)}$ Whilst their use in $\mathrm{ACHD}$ is increasing, their success is mainly reported in a number of case reports with no large randomised trial available to date. Furthermore, patients with CHD listed for cardiac transplantation are less likely to have mechanical support, including a VAD, than those with acquired heart failure. ${ }^{(78,90)}$

As discussed above, univentricular hearts account for the greatest number of CHD referrals for transplant. Thus, there has been much interest in the benefit of VADs in this growing population. A number of case reports have shown that VADs in patients with a Fontan circulation can facilitate the recovery of circulatory, metabolic and pulmonary abnormalities. ${ }^{(91,92)}$ They can be beneficial if the underlying problem is ventricular dysfunction ${ }^{(93)}$ or normal ventricular function but high venous pressures. ${ }^{(94)}$ However, previous studies have shown that showed that in children with univentricular circulations, the use of the Berlin heart VAD was associated with only a $50 \%$ chance of survival to transplantation compared to an overall survival of $70-86 \%$ in all children with a VAD. ${ }^{(95-97)}$ New devices that specifically increase 
the blood flow through the systemic venous return through the lungs are being designed, for example a pump in the IVC and hepatic blood flow to give mechanical cavopulmonary assistance. ${ }^{(98)}$

Similarly, case reports have reported some success with the use of VADs in patients with systemic right ventricles. ${ }^{(99,100)}$ Joyce, et al. however report complications arising from the positioning of the cannulae due anatomical differences in the right ventricle. ${ }^{(99)}$

\section{END OF LIFE CARE}

The role of early and proactive discussion regarding end of life (EOL) care is of proven benefit in oncology and acquired heart failure ${ }^{(101-103)}$ and leads to less aggressive medical care at the end of life and earlier referral for hospice care. However, a recent study by Tobler, et al. reported that in a survey of adults with $\mathrm{CHD}$, only $1 \%$ of patients had discussed $\mathrm{EOL}$ planning, whereas $50 \%$ of their physicians reported regularly discussing these issues. ${ }^{(104)}$ Furthermore they found that $78 \%$ of these patients wished to discuss EOL issues, $62 \%$ wishing for this to be done at an early stage and this was irrespective of disease severity. A further study by this group looked at the experience of adults with CHD who died in hospital and found that only 10\% had documented EOL discussions with active resuscitation less likely to happen in these patients. ${ }^{(105)}$

As cardiologists we frequently extrapolate our experience from that gained in acquired heart failure including in EOL care. However, patients with $\mathrm{CHD}$ have important differences. Firstly they have a lifelong illness and there is often no triggering event for the deterioration, making timing of discussion difficult to judge in many cases. ${ }^{(106)}$ Furthermore, these patients are young with the median age of patients with severe CHD being just 29 years. ${ }^{(4)}$ With increasing survivors of the Norwood operation now reaching adulthood, the number of young adults is likely to increase.

Oncologists have identified that young patients have unique needs, often needing a more collaborative approach with their physician with regards to their care planning. ${ }^{(107)}$ A previous study in young patients with cancer showed that EOL discussions often don't occur until very close to death, with barriers to communication including a desire to protect and difficulties dealing with personal emotions. ${ }^{(108)}$

There is frequently a difficult balance between life-prolonging interventions, such as transplantation, and end of life care. Ideally patients should have a parallel approach to their care with a study looking at patients with acquired heart failure being assessed for VADs showing that this approach leads to clearer post-operative care and more effective management of complications. ${ }^{(109)}$

As the number of patients with advanced disease continues to increase, we must acknowledge that this is an important, and currently often lacking, part of our patients' on-going care. EOL discussion and planning should become a routine part of their assessment and their unique needs and preferences addressed. ${ }^{(106)}$

\section{CONCLUSION}

Patients with complex congenital heart disease are a growing population and remain at lifelong risk of complications. Whilst drug therapy is usually the first line treatment in advanced disease, results from conventional therapy are disappointing, although there are promising results from the use of selective pulmonary vasodilators in patients with a Fontan circulation. However, whilst medical options may slow down the progression and even delay the need for surgical intervention or transplantation, they do not halt the inevitable decline altogether. Whilst transplantation in patients with CHD is associated with higher early mortality post transplantation, the long term survival is equivalent to that in acquired heart failure. Many patients though are not suitable for listing or die on the waiting list. These issues highlight the importance of end of life discussion and planning, an area that, as a speciality, we frequently fail to address. Delivering optimal EOL care in this population remains one of the big challenges we continue to face. Finally, CHD is a lifelong condition and thus requires lifelong access to health care. Many of the treatment options discussed in this review, especially devices and cardiac transplantation may be prohibitively expensive to some patients where free health care is not available to all.

\section{Conflict of interest: none declared.}




\section{REFERENCES}

I. Moons P, Bovijn L, Budts W, et al. Temporal trends in survival to adulthood among patients born with congenital heart disease from 1970 to 1992 in Belgium/ Clinical Perspective. Circulation 2010; 122:2264-2272.

2. Warnes CA, Liberthson R, Danielson J, et al. Task Force I: The changing profile of congenital heart disease in adult life. J Am Coll Cardiol 2001;37:1 170-1 175.

3. Nieminen HP, Jokinen EV, Sairanen HI. Causes of late deaths after paediatric cardiac surgery: A population-based study. Journal of the American College of Cardiology 2007;50:1263-127|

4. Marelli AJ, Mackie AS, lonescu-Ittu R, et al. Congenital heart disease in the general population. Circulation 2007; I 15:163-172.

5. Silversides CK, Salehian O, Oechslin E, et al. Canadian Cardiovascular Society 2009 Consensus Conference on the management of adults with congenital heart disease: Complex congenital cardiac lesions. Canadian Journal of Cardiology 2010;26:e98-el17

6. Tutarel O, Kempny A, Onso-Gonzalez R, et al. Congenital heart disease beyond the age of 60 : emergence of a new population with high resource utilisation, high morbidity, and high mortality. European Heart Journal 2013.

7. Khairy P, lonescu-lttu R, Mackie AS, et al. Changing mortality in congenital heart disease. J Am Coll Cardiol 20 10;56:1 |49-1 I57.

8. Verheugt CL, Uiterwaal CSPM, van der Velde ET, et al. Mortality in adult congenital heart disease. European Heart Journal 2010;31:1220-1229.

9. Zomer AC, Vaartjes I, Uiterwaal CSPM, et al. Circumstances of death in adult congenital heart disease. International Journal of Cardiology 20 I2; I 54:168- 172.

10. Oechslin EN, Harrison DA, Connelly MS, et al. Mode of death in adults with congenital heart disease. The American Journal of Cardiology 2000;86: I I I I- I I I6.

I I. Afilalo J, Therrien J, Pilote L, et al. Geriatric congenital heart disease: Burden of disease and predictors of mortality. J Am Coll Cardiol 201 1;58:1509-15।5.

12. Roche SL, Redington AN. The failing right ventricle in congenital heart disease. Canadian Journal of Cardiology 2013;29:768-778.

13. Wilson NJ, Clarkson PM, Barratt-Boyes BG, et al. Long-term outcome after the mustard repair for simple transposition of the great arteries: 28-year follow-up. J Am Coll Cardiol 1998;32:758-765.

14. Piran S, Veldtman G, Siu S, et al. Heart failure and ventricular dysfunction in patients with single or systemic right ventricles. Circulation 2002; 105: I I89- I 194.

15. Ebenroth ES, Hurwitz RA. Functional outcome of patients operated for d-transposition of the great arteries with the Mustard procedure. The American Journal of Cardiology 2002;89:353-356.

16. Graham TP, Bernard YD, Mellen BG, et al. Long-term outcome in congenitally corrected transposition of the great arteries: A multi-institutional study. J Am Coll Cardiol 2000;36:255-261.

17. Therrien J, Provost $Y$, Harrison J, et al. Effect of angiotensin receptor blockade on systemic right ventricular function and size: A small, randomised, placebocontrolled study. International Journal of Cardiology 2008; 129:187-192.

18. Millane T, Bernard EJ, Jaeggi E, et al. Role of ischaemia and infarction in late right ventricular dysfunction after atrial repair of transposition of the great arteries. Journal of the American College of Cardiology 2000;35:1661 - 1668.

19. Lubiszewska B, Gosiewska E, Hoffman P, et al. Myocardial perfusion and function of the systemic right ventricle in patients after atrial switch procedure for complete transposition: Long-term follow-up. Journal of the American College of Cardiology 2000;36: I 365-1370

20. Brilla CG, Funck RC, Rupp H. Lisinopril-mediated regression of myocardial fibrosis in patients with hypertensive heart disease. Circulation 2000; 102: 1 388-1393.

21. Consensus Trial Study Group. Effects of enalapril on mortality in severe congestive heart failure. N Engl J Med 1987;316:1429-|435.
22. SOLVD investigators. Effect of enalapril on survival in patients with reduced left ventricular ejection fractions and congestive heart failure. N Engl J Med 1991:325:293-302.

23. Granger CB, McMurray JJ, Yusuf S, et al. Effects of candesartan in patients with chronic heart failure and reduced left-ventricular systolic function intolerant to angiotensin-converting-enzyme inhibitors: The CHARM-Alternative trial. The Lancet 2003;362:772-776.

24. Dore A, Houde C, Chan KL, et al. Angiotensin receptor blockade and exercise capacity in adults with systemic right ventricles: A multicenter, randomised, placebo-controlled clinical trial. Circulation 2005; I 12:241 I-2416.

25. Hechter SJ, Fredriksen PM, Liu P, et al. Angiotensin-converting enzyme inhibitors in adults after the mustard procedure. The American Journal of Cardiology 2001;87:660-663

26. Van der Bom T, Winter MM, Bouma BJ, et al. Effect of valsartan on systemic right ventricular function: A double-blind, randomised, placebo-controlled pilot trial. Circulation 2013:127:322-330.

27. Packer M, Coats AJS, Fowler MB, et al. Effect of carvedilol on survival in severe chronic heart failure. N Engl J Med 2001;344:1651-1658.

28. Groenning BA, Nilsson JC, Sondergaard L, et al. Antiremodeling effects on the left ventricle during beta-blockade with metoprolol in the treatment of chronic heart failure. Journal of the American College of Cardiology 2000;36:2072-2080.

29. Josephson CB, Howlett JG, Jackson SD, et al. A case series of systemic right ventricular dysfunction post atrial switch for simple D-transposition of the great arteries: The impact of beta-blockade. Canadian Journal of Cardiology 2006;22:769-772

30. Giardini A, Lovato L, Donti A, et al. A pilot study on the effects of carvedilol on right ventricular remodelling and exercise tolerance in patients with systemic right ventricle. International Journal of Cardiology 2007; | 14:241-246.

31. Doughan AR, McConnell ME, Book WM. Effect of beta blockers (Carvedilol or Metoprolol $\mathrm{XL}$ ) in patients with transposition of great arteries and dysfunction of the systemic right ventricle. The American Journal of Cardiology 2007; 99:704-706.

32. Dos L, Pujadas S, Estruch M, et al. Eplerenone in systemic right ventricle: Double blind randomised clinical trial. The evedes study. International Journal of Cardiology.

33. Cedars A, Joseph S, Ludbrook P. Heart failure in adults who had the Fontan procedure: Natural history, evaluation, and management. Curr Treat Options Cardio Med 2013;1-15.

34. Rathod RH, Prakash A, Powell AJ, et al. Myocardial fibrosis identified by cardiac magnetic resonance late gadolinium enhancement is associated with adverse ventricular mechanics and ventricular tachycardia late after Fontan operation. Journal of the American College of Cardiology 20 10;55:1721 - 1728.

35. Ishibashi N, Park IS, Waragai T, et al. Effect of Carvedilol on heart failure in patients with a functionally univentricular heart. Circulation Journal 2011;75: 1394-1399.

36. Hsu DT, Zak V, Mahony L, et al. For the Paediatric Heart Network Investigators: Enalapril in infants with single ventricle: Results of a multicenter randomised trial. Circulation 2010; 122:333-340.

37. Mitchell MB, Campbell DN, Ivy D, et al. Evidence of pulmonary vascular disease after heart transplantation for Fontan circulation failure. The Journal of Thoracic and Cardiovascular Surgery 2004; 128:693-702.

38. Kouatli AA, Garcia JA, Zellers TM, et al. Enalapril does not enhance exercise capacity in patients after Fontan procedure. Circulation 1997;96:1507-1512.

39. Schuuring MJ, Vis JC, Bouma BJ, et al. Rationale and design of a trial on the role of bosentan in Fontan patients: Improvement of exercise capacity? Contemporary Clinical Trials 201 1;32:586-591. 
40. Goldberg DJ, French B, McBride MG, et al. Impact of oral sildenafil on exercise performance in children and young adults after the Fontan operation: A randomised, double-blind, placebo-controlled, crossover trial. Circulation 201 I; 123:1185-1193.

4I. Ovaert C, Thijs D, Dewolf D, et al. The effect of bosentan in patients with a failing Fontan circulation. Cardiology in the Young 2009; 19:331-339.

42. Bowater SE, Weaver RA, Thorne SA, et al. The safety and effects of Bosentan in patients with a Fontan circulation. Congenital Heart Disease 201 2;7:243-249.

43. Shabanian R, Shahbaznejad L, Razaghian A, et al. Sildenafil and Ventriculo-Arterial Coupling in Fontan-Palliated patients: A noninvasive echocardiographic assessment. Pediatr Cardiol 2013;34:129-134.

44. Khairy $\mathrm{P}$, lonescu-Ittu R, Mackie AS, et al. Changing mortality in congenital heart disease. J Am Coll Cardiol 20 10;56:1 I49-1 I57.

45. Silka MJ, Hardy BG, Menashe VD, et al. A population-based prospective evaluation of risk of sudden cardiac death after operation for common congenital heart defects. Journal of the American College of Cardiology 1998;32:245-25I.

46. Walsh EP, Cecchin F. Arrhythmias in adult patients with congenital heart disease. Circulation 2007:1 1 5:534-545.

47. Abadir S, Khairy P. Electrophysiology and adult congenital heart disease: Advances and options. Progress in cardiovascular diseases 2011;53:281-292.

48. Nollert G, Fischlein $T$, Bouterwek $S$, et al. Long-term survival in patients with repair of Tetralogy of Fallot: 36-year follow-up of 490 survivors of the first year after surgical repair. Journal of the American College of Cardiology 1997; 30:1374-1383.

49. Kammeraad JAE, van Deurzen CHM, Sreeram N, et al. Predictors of sudden cardiac death after mustard or senning repair for transposition of the great arteries. Journal of the American College of Cardiology 2004;44: 1095- I 02.

50. Schwerzmann M, Salehian O, Harris L, et al. Ventricular arrhythmias and sudden death in adults after a Mustard operation for transposition of the great arteries. European Heart Journal 2009;30:1873-1879.

5I. Czosek RJ, Anderson J, Khoury PR, et al. Utility of ambulatory monitoring in patients with congenital heart disease. The American Journal of Cardiology 2013; | 1 1:723-730.

52. Gatzoulis MA, Till J, Somerville J, Redington AN. Mechano-electrical interaction in tetralogy of Fallot: QRS prolongation relates to right ventricular size and and predicts malignant vebtricular arrhythmias and sudden death. Circulation 1995;92:231-237.

53. Gatzoulis MA, Balaji S, Webber SA, et al. Risk factors for arrhythmia and sudden cardiac death late after repair of tetralogy of Fallot: A multicentre study. The Lancet 2000;356:975-98।.

54. Khairy P, Landzberg MJ, Gatzoulis MA, et al. Value of programmed ventricular stimulation after Tetralogy of Fallot repair: A multicenter study. Circulation 2004; 109:1994-2000.

55. Khairy P, Harris L, Landzberg MJ, et al. Implantable cardioverter-defibrillators in Tetralogy of Fallot. Circulation 2008; 1 17:363-370.

56. Khairy $\mathrm{P}$, Harris L, Landzberg MJ, et al. Sudden death and defibrillators in transposition of the great arteries with intra-atrial baffles: A multicenter study. Circulation: Arrhythmia and Electrophysiology 2008.

57. Yap SC, Roos-Hesselink JW, Hoendermis ES, et al. Outcome of implantable cardioverter defibrillators in adults with congenital heart disease: a multicentre study. European Heart Journal 2007;28: | 854- |86|.

58. Berul Cl, Van Hare GF, Kertesz NJ, et al. Results of a multicenter retrospective implantable cardioverter-defibrillator registry of paediatric and congenital heart disease patients. Journal of the American College of Cardiology 2008;5 I: 1685- I69 I.
59. Tomaske M, Bauersfeld U: Experience with implantable cardioverter-defibrillator therapy in grown-ups with congenital heart disease. Pacing \& clinical electrophysiology 2008;31:S35-S37.

60. Khanna AD, Warnes CA, Phillips SD, et al. Single-center experience with implantable cardioverter-defibrillators in adults with complex congenital heart disease. The American Journal of Cardiology 20 I I; 108:729-734.

6I. Koyak Z, de Groot JR, Van Gelder IC, et al. Implantable cardioverter defibrillator therapy in adults with congenital heart disease: Who is at risk of shocks? Circulation: Arrhythmia and electrophysiology 2012;5:101-110.

62. Jarman JWE, Lascelles $K$, Wong $T$, et al. Clinical experience of entirely subcutaneous implantable cardioverter-defibrillators in children and adults: Cause for caution. European Heart Journal 2012;33:1351-1359.

63. Mondesert B, Abadir S, Khairy P. Arrhythmias in adult congenital heart disease: The year in review. Curr Opin Cardiol 2013;28:354-359.

64. DeMaso DR, Lauretti A, Spieth L, et al. Psychosocial factors and quality of life in children and adolescents with implantable cardioverter-defibrillators. The American Journal of Cardiology 2004:93:582-587.

65. Walsh EP. Practical aspects of implantable defibrillator therapy in patients with congenital heart disease. Pacing and clinical electrophysiology 2008;31:S38-S40.

66. Bristow MR, Saxon LA, Boehmer J, et al. Cardiac-resynchronisation therapy with or without an implantable defibrillator in advanced chronic heart failure. $N$ Engl J Med 2004;350:2140-2150.

67. Cleland JGF, Daubert JC, Erdmann E, et al. The effect of cardiac resynchronisation on morbidity and mortality in heart failure. N Engl J Med 2005;352: I539-I 549.

68. Janousek J. Gebauer RA. Cardiac resynchronisation therapy in paediatric and congenital heart disease. pacing and clinical electrophysiology 2008:31:S21-S23.

69. Khairy P, Fournier A, Thibault B, et al. Cardiac resynchronisation therapy in congenital heart disease. International Journal of Cardiology 2006; 109:160-168.

70. Janousek J, Gebauer RA, Bdul-Khaliq H, et al. For the working group for cardiac dysrhythmias and electrophysiology of the Association for European Paediatric Cardiology: Cardiac resynchronisation therapy in paediatric and congenital heart disease: differential effects in various anatomical and functional substrates. Heart 2009;95:। 165-1171.

7I. Dubin AM, Janousek J, Rhee E, et al. Resynchronisation therapy in paediatric and congenital heart disease patients: An International multicenter study. Journal of the American College of Cardiology 2005;46:2277-2283.

72. Janousek J, Tomek V. Chaloupeck V, et al. Cardiac resynchronisation therapy: A novel adjunct to the treatment and prevention of systemic right ventricular failure. Journal of the American College of Cardiology 2004;44:1927-1931.

73. Petko M, Myung RJ, Wernovsky G, et al. Surgical reinterventions following the Fontan procedure. European Journal of Cardio-Thoracic Surgery 2003; 24:255-259.

74. Patel ND, Weiss ES, Allen JG, et al. Heart transplantation for adults with congenital heart disease: Analysis of the United Network for Organ Sharing Database. Ann Thorac Surg 2009:88:814-822.

75. Bhama JK, Shulman J, Bermudez CA, et al. Heart transplantation for adults with congenital heart disease: Results in the modern era (abstract). J Heart Lung Transplant 20 13;32:499-504.

76. Irving C, Parry G, O'Sullivan J, et al. Cardiac transplantation in adults with congenital heart disease. Heart 2010;96:1217-1222.

77. Taylor DO, Edwards LB, Boucek MM, et al. Registry of the International Society for Heart and Lung Transplantation: Twenty-fourth official adult heart transplant report, 2007 (abstract). J Heart Lung Transplant 2007;26:769-78I. 


\section{REFERENCES}

78. Davies RR, Russo MJ, Yang J, et al. Listing and transplanting adults with congenital heart disease/clinical perspective. Circulation 20 I I;123:759-767.

79. Kirklin JK, Naftel DC, Kormos RL, et al. Third Intermacs annual report: The evolution of destination therapy in the United States (abstract). J Heart Lung Transplant 201 1;30:1 15-123.

80. Meyer SR, Campbell PM, Rutledge JM, et al. Use of an allograft patch in repair of hypoplastic left heart syndrome may complicate future transplantation. European Journal of Cardio-Thoracic Surgery 2005;27:554-560.

81. Nwakanma LU, Williams JA, Weiss ES, et al. Influence of pretransplant panelreactive antibody on outcomes in 8160 heart transplant recipients in recent era. The Annals of Thoracic Surgery 2007;84:1556-1563.

82. Deal BJ, Jacobs ML. Management of the failing Fontan circulation. Heart 2012;98: 1098-। 104.

83. Van der Pluym C, Urschel S, Buchholz $\mathrm{H}$. Advanced therapies for congenital heart disease: ventricular assist devices and heart transplantation. Canadian Journal of Cardiology 2013;29:796-802

84. Karamlou T, Diggs BS, Welke $K$, et al. Impact of single-ventricle physiology on death after heart transplantation in adults with congenital heart disease. Ann Thorac Surg 2012.

85. Griffiths ER, Kaza AK, Wyler von Ballmoos MC,et al. Evaluating failing Fontans for heart transplantation: Predictors of death. The Annals of Thoracic Surgery 2009;88:558-564.

86. Emin A, Rogers CA, Parameshwar J, et al. On behalf of the steering group of the UK Cardiothoracic Transplant Audit and the UK VAD Forum: Trends in longterm mechanical circulatory support for advanced heart failure in the UK. European Journal of Heart Failure 2013.

87. Rose EA, Moskowitz AJ, Packer M, et al. The rematch trial: Rationale, design, and end points. The Annals of Thoracic Surgery 1999;67:723-730.

88. Slaughter MS, Rogers JG, Milano CA, et al. Advanced heart failure treated with continuous-flow left ventricular assist device. N Engl J Med 2009;361:2241-225।.

89. Kilic A, Ailawadi G. Left ventricular assist devices in heart failure. Expert review of cardiovascular therapy 2012, 10:649-656

90. Everitt MD, Donaldson AE, Stehlik J, et al. Would access to device therapies improve transplant outcomes for adults with congenital heart disease? Analysis of the United Network for Organ Sharing (UNOS) (abstract). J Heart Lung Transplant 2011;30:395-401.

91. Shah NR, Lam WW, Rodriguez FH, et al. Clinical outcomes after ventricular assist device implantation in adults with complex congenital heart disease (abstract). J Heart Lung Transplant 2013;32:615-620.

92. Irving CA, Cassidy JV, Kirk RC, et al. Successful bridge to transplant with the Berlin heart after cavopulmonary shunt [abstract]. J Heart Lung Transplant 2009;28:399-40।

93. Frazier $\mathrm{OH}$, Gregoric I, Messner D. Total circulatory support with an LVAD in an adolescent with a previous Fontan procedure. Tex Heart Inst J 2005;32:402-404.

94. Prêtre R, Häussler A, Bettex D, Genoni M. Right-sided univentricular cardiac assistance in a failing Fontan circulation. The Annals of Thoracic Surgery 2008;86:1018-1020

95. Van der Pluym C], Rebeyka IM, Ross DB, et al. The use of ventricular assist devices in paediatric patients with univentricular hearts. The Journal of Thoracic and Cardiovascular Surgery 2011;41:588-590

96. Blume ED, Naftel DC, Bastardi HJ, et al. For the Paediatric Heart Transplant Study Investigators: Outcomes of children bridged to heart transplantation with ventricular assist devices: A multi-institutional study. Circulation 2006; | 13: 2313-2319.
97. Morales DLS, Almond CSD, Jaquiss RDB, et al. Bridging children of all sizes to cardiac transplantation: The initial multicenter North American experience with the Berlin Heart Excor ventricular assist device (abstract). J Heart Lung Transplant 2011;30:1-8.

98. Kapadia JY, Pierce KC, Poupore AK, et al. Hydraulic testing of intravascular axial flow blood pump designs with a protective cage of filaments for mechanical cavopulmonary assist. ASAIO Journal 2010;56.

99. Joyce DL, Crow SS, John R, et al. Mechanical circulatory support in patients with heart failure secondary to transposition of the great arteries (abstract). J Heart Lung Transplant 20 10;29:1 302-। 305.

100. Agusala K, Bogaev R, Frazier OH, et al. Ventricular assist device placement in an adult with d-transposition of the great arteries with prior mustard operation. Congenital Heart Disease 20 10;5:635-637.

101. Catherine M, Paul S, Lorraine W, et al. Information needs of cancer patients in west Scotland: Cross sectional survey of patients' views. BMJ 1996;313.

102. McCarthy M, Hall JA, Ley M. Communication and choice in dying from heart disease. JRSM 1997;90: |28-131.

103. Gibbs JSR, McCoy ASM, Gibbs LME, et al. Living with and dying from heart failure: The role of palliative care. Heart 2002;88:ii36-ii39.

I04. Tobler D, Greutmann M, Colman JM, et al. End-of-life in adults with congenital heart disease: A call for early communication. International Journal of Cardiology 2012;155:383-387.

105. Tobler D, Greutmann M, Colman JM, et al. End-of-life care in hospitalised adults with complex congenital heart disease: care delayed, care denied. Palliative Medicine 2012;26:72-79.

106. Bowater SE, Speakman JK, Thorne SA. End-of-life care in adults with congenital heart disease: Now is the time to act. Current opinion in supportive and palliative care 2013;7.

107. Brown VA, Parker PA, Furber L, et al. Patient preferences for the delivery of bad news - the experience of a UK Cancer Centre. European Journal of Cancer Care 2011;20:56-61.

108. Bell C, Skiles J, Pradhan K, et al. End-of-life experiences in adolescents dying with cancer. Supportive Care in Cancer 2010;8:827-835.

109. Swetz KM, Freeman MR, AbouEzzeddine OF, et al. Palliative medicine consultation for preparedness planning in patients receiving left ventricular assist devices as destination therapy. Mayo Clinic Proceedings 201 1;86:493-500. 